\title{
Note on Transcriptions and \\ Biblical and Rabbinical Quotations
}

The transcription from Hebrew and Aramaic follows the norms of the Encyclopedia Judaica, with a few simplifications. Diacritic signs are not used. No distinction is made between alefand ayin. He and het are both transcribed as $h$. The $u$ should always be read as "oo," and the $e$ is always short.

Some words (such as those of certain feasts or bodies of work) and some personal names, however, appear in a form more commonly used in English, even when this departs from the general transcription norms used in this book.

As a general rule, biblical quotations follow the Jewish Publication Society's Tanakh Translation (1985, 1999) in The Jewish Study Bible (Oxford University Press, 2003, 2004). But in a few cases, where the context demands it, the text may differ from this translation. Except where indicated, all other translations from the Hebrew are by the author and translator. 
